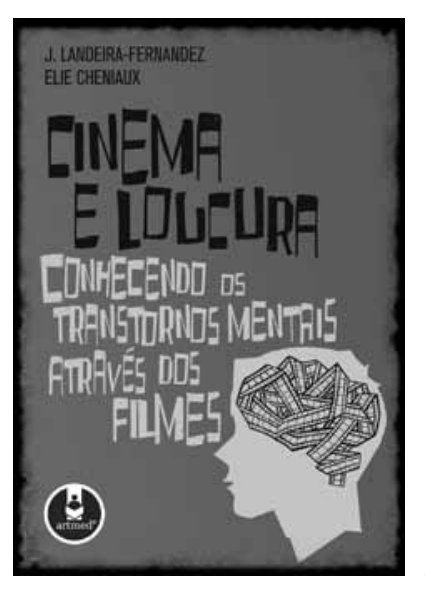

\title{
Cinema e loucura: conhecendo os transtornos mentais através dos filmes
}

\author{
J. Landeira-Fernadez e Elie Cheniaux \\ Porto Alegre, Artmed, 2010, 287 páginas \\ Jorge Luiz Lena Andreta1 ${ }^{1}$, Rachel Loureiro Andreta², Bárbara Loureiro Andreta ${ }^{3}$
}

O livro Cinema e loucura: conhecendo os transtornos mentais através dos filmes, de autoria de J. Landeira-Fernadez e Elie Cheniaux, é uma bem elaborada revisão do Diagnostic and Statistical Manual of Mental Disorders, 4th edition, Text Revision (DSM-IV-TR), onde os filmes assumem papel ilustrativo, possibilitando ao leitor compreender muitas das características e das manifestações de transtornos mentais através da associação com famosos personagens do cinema.

A obra é dividida em 15 capítulos, compondo um total de 287 páginas. No primeiro capítulo, a Introdução, os autores fazem um apanhado histórico das questões que envolvem saúde mental, abordando temas como o movimento psicanalítico, a antipsiquiatra, a revolução dos fármacos e a psiquiatria no Brasil. Ilustrando todo esse caminho percorrido pela saúde mental, fazem-se presentes nesse capítulo grandes produções cinematográficas, a saber: Joana D'Arc de Luc Besson, As loucuras do Rei George, Contos proibidos do Marquês de Sade, Freud além da alma, Um estranho no ninho e o nacional Bicho de sete cabeças.

O segundo capítulo, intitulado "Transtornos cognitivos", aborda delirium, demência e transtorno amnéstico. Os autores informam que o DSM-IV-TR classifica os transtornos cognitivos usando as três categorias citadas acima (delirium, demência e transtorno amnéstico), e que, em cada um desses transtornos, há comprometimento da fisiologia ou de estruturas cerebrais. Os filmes
Iris, Réquiem para um sonho e Procurando Nemo estão entre os utilizados para ilustrar os transtornos cognitivos em questão.

O terceiro capítulo, "Transtornos mentais relacionados a substâncias", é cuidadosamente dividido entre transtornos mentais relacionados ao álcool, transtornos mentais relacionados à anfetamina, transtornos mentais relacionados a alucinógenos e transtornos mentais relacionados a opioides. Os autores relembram que os transtornos mentais relacionados a substâncias podem ser classificados em cinco categorias: abuso, dependência, intoxicação, abstinência e transtornos induzidos por substâncias como uma consequência fisiológica direta de sua ação. Filmes-referência no assunto como Eu, Cristiane F., 13 anos, drogada e prostituída e Diário de um adolescente são muito bem trabalhados nesse capítulo, assim como Johnny \& June e Meu nome não é Johnny.

Os "Transtornos psicóticos", que correspondem à profunda discordância entre o sujeito e o ambiente em que ele se encontra, são explorados no capítulo 4. Esses transtornos estão divididos da seguinte forma: esquizofrenia, transtorno delirante (subtipos persecutório, de ciúmes, erotomaníaco, de grandeza e somático), transtorno psicótico induzido, transtorno psicótico leve e o que os autores nomearam de "loucuras mal definidas". Uma mente brilhante, Estamira, Camille Claudel e Betty Blue foram alguns dos filmes utilizados como referência. Destaca-se, entretanto, que, no caso do transtorno

${ }^{1}$ Médico psiquiatra. Especialista em Psiquiatria, Associação Brasileira de Psiquiatria e Associação Médica Brasileira. ${ }^{2}$ Psicóloga. ${ }^{3}$ Psicóloga. Especialização em Psicologia Clínica: Escutas da Infância, Centro Universitário Franciscano, Santa Maria, RS.

Recebido em 01/12/2010. Aceito em 02/03/2011. Não foram declarados conflitos de interesse associados à publicação desta resenha.

Como citar: Andreta JLL, Andreta RL, Andreta BL. Cinema e loucura: conhecendo os transtornos mentais através dos filmes [resenha]. Trends Psychiatry Psychother. $2011 ; 33(3): 189-91$. 
esquizofreniforme, os autores não encontraram filmes que ilustrassem o transtorno.

Os "Transtornos do humor" correspondem ao capítulo 5 do livro. De acordo com os autores, nesses transtornos se percebe uma expressão exagerada de alegria, irritabilidade ou tristeza, da qual decorrem as demais alterações psicopatológicas. Dentre os transtornos do humor são estudados o transtorno bipolar, o transtorno depressivo maior e o transtorno distímico. O clássico Amadeus e sucessos como Pequena Miss Sunshine e As horas entram em cena para exemplificar aos leitores os transtornos de humor.

O capítulo 6, "Transtornos de ansiedade", remete aos transtornos mentais mais prevalentes, em que não ocorrem sintomas psicóticos, sendo a ansiedade a manifestação principal. Esse capítulo engloba vários transtornos, incluindo transtorno de pânico, agorafobia sem história de pânico, fobia social, fobia específica, transtorno obsessivo-compulsivo, transtorno de estresse pós-traumático, transtorno de estresse agudo e transtorno de ansiedade generalizada. Como exemplos de transtornos de ansiedade são abordados filmes como Máfia no divã, O aviador, Nascido em 4 de julho e Freud além da alma.

Os "Transtornos somatoformes" compõem o capítulo 7 dessa obra. Os transtornos desse grupo caracterizam-se pela presença de sintomas físicos que não podem ser explicados por uma condição médica geral. São trabaIhados transtorno conversivo, transtorno de somatização, transtorno hipocondríaco e transtorno dismórfico-corporal. Os filmes Freud além da alma, Meu primeiro amor e Cyrano de Bergerac prestam-se como exemplos cinematográficos desses transtornos.

O capítulo 8 aborda "Transtornos dissociativos", que correspondem a um prejuízo parcial ou total das funções normalmente integradas de consciência, memória e identidade. Compõem o capítulo: fuga dissociativa, transtorno de transe dissociativo, transtorno dissociativo de identidade e estupor dissociativo. Para o estudo de tais transtornos, foram usados filmes como $A$ enfermeira Betty, Psicose e Asas da liberdade.

O capítulo 9 é dedicado a "Transtornos factícios e simulação", que são definidos pelos autores como quadros nos quais o sujeito simula ou provoca sinais ou sintomas físicos ou psicológicos com o único intuito de receber atenção e cuidados médicos. Filmes como Um estranho no ninho, Refém do silêncio e M.A.S.H. ilustram as características e manifestações desse transtorno.

O capítulo 10 do livro contempla os "Transtornos da sexualidade". Segundo os autores, o conceito de transtorno da sexualidade relaciona-se à expressão do comportamento sexual deficiente ou excessiva, bem como a qualquer condição que cause sofrimento, culpa, prejuízo ou moléstia para si ou para a pessoa que participa do relacionamento sexual. O presente capítulo divide-se em transtorno da identidade de gênero, disfunções sexuais e parafilias, e utiliza os seguintes filmes para exemplificar os transtornos: Meninos não choram, Priscilla: a rainha do deserto, Repulsa ao sexo, Psicose e Lolita.

Os "Transtornos da alimentação" aparecem no capítulo 11 da presente obra, trazendo a anorexia nervosa e a bulimia nervosa como os transtornos mais prevalentes em nossa sociedade. Esses transtornos se caracterizam por uma preocupação excessiva quanto ao peso e à forma física, estando muito relacionados à valorização da magreza, que é vista como sinônimo de beleza nas sociedades ocidentais. Os filmes Maus hábitos, O preço da perfeição e Tiros na Broadway mostram ao leitor de forma bem ilustrativa tais transtornos.

No capítulo 12, os autores trabalham os "Transtornos do sono", ou seja, as alterações do sono que são independentes de outros transtornos mentais, do uso de uma substância psicoativa ou de uma condição médica geral (transtornos primários do sono). São analisados a insônia primária, a narcolepsia, o transtorno do ritmo circadiano do sono, o transtorno de pesadelo e sonambulismo. Para ilustrar tais transtornos, os autores trazem filmes famosos da indústria cinematográfica, como Clube da luta, Moulin Rouge - Amor em vermelho, E o vento levou e Donnie Darko.

O capítulo 13, ao trabalhar os "Transtornos do controle dos impulsos", revela-se um dos capítulos mais interessantes do livro. Segundo os autores, tais transtornos não apresentam o comprometimento de outras funções mentais necessárias para o diagnóstico de outra categoria nosológica. Casos como transtorno explosivo intermitente, piromania, cleptomania e jogo patológico são estudados neste capítulo e muito bem exemplificados por filmes como Betty Blue, Contos proibidos do Marquês de Sade e $O$ sonho de Cassandra.

Assim como o capítulo anterior, o capítulo 14, "Transtornos da personalidade", apresenta-se longo e extremamente interessante. Os autores lembram que os transtornos da personalidade são muito mais do que traços de personalidade: eles caracterizam-se por um padrão mal-adaptativo, enraizado e inflexível de comportamento, reações emocionais e formas de se relacionar com outras pessoas. Vários transtornos são abordados neste capítulo, a saber: transtorno da personalidade paranoide, transtorno da personalidade esquizoide, transtorno da personalidade antissocial, transtorno da personalidade borderline (limítrofe), transtorno da personalidade histriônica, transtorno da personalidade narcisista, transtorno da personalidade dependente e transtorno da personalidade obsessivo-compulsiva. Para ilustrar esses transtornos, diversos filmes foram cuidadosamente e muito bem escolhidos pelos autores: $A$ conversão, $O$ 
último lance, Cassino, Um estranho no ninho, O silêncio dos inocentes, Jornada da alma, Garota interrompida, Melhor é impossível.

Por último, mas não menos importante, o capítulo 15 aborda os "Transtornos mentais da infância e da adolescência". Os autores chamam atenção para o fato de que não existem transtornos mentais exclusivos da infância e da adolescência. Desta forma, as razões pelas quais esses transtornos aparecem em um capítulo separado são apenas de ordem prática, com o objetivo de salientar os transtornos que se originam nessas fases inicias do desenvolvimento. Nesse capítulo aparecem transtornos como retardo mental, transtornos globais do desenvolvimento, transtornos da aprendizagem, transtorno de déficit de atenção/hiperatividade, transtorno de conduta, transtornos da comunicação e transtornos de tique. Para realizar a ilustração de tais transtornos, os autores escolheram filmes como Nell, O enigma de Kaspar Hauser,
Código para o inferno, Pearl Harbor e Laranja Mecânica.

O interessante nesse livro é, justamente, a união de uma forma de arte com o estudo dos transtornos mentais, o que tornou a leitura mais dinâmica e instigante e, consequentemente, mais produtiva. Considerando que o cinema retrata conteúdos objetivos e subjetivos do ser humano e da sociedade em que este está inserido, o livro é um perfeito elo de ligação entre as artes visuais e os estudos em saúde mental. Iniciativas como a desses autores motivam os leitores a compreender não só a dimensão dos transtornos mentais, mas também a relação existente entre as artes e o estudo da saúde mental.

\section{Correspondência}

Jorge Luiz Lena Andreta

Rua João Escobar Carpes, 926, Bairro Maria Alice Gomes

97700-000 - Santiago, RS - Brasil

Tel.: (55) 32514352 / (55) 99793876

E-mail: jorgeandreta@hotmail.com 